\title{
Engaging frontline providers: an important key to eliminating tuberculosis in Canada, and other high-income countries
}

\author{
Courtney Heffernan ${ }^{1} \cdot$ Brian H. Rowe ${ }^{1,2,3} \cdot$ Richard Long ${ }^{1,3}$
}

Received: 5 April 2021 / Accepted: 17 June 2021 / Published online: 13 September 2021

(C) The Canadian Public Health Association 2021

\begin{abstract}
The greatest human cost of the rapidly moving pandemic of SARS-CoV-2 may be due to its impact on the response to other diseases. One such other disease is tuberculosis (TB). All indications suggest that COVID-19-related diversions of healthcare resources and disruptions to public health programming will exacerbate the slower moving pandemic of TB. This is expected to set back TB elimination efforts by years. This is a prediction that is especially relevant to Canada, which has repeatedly failed to meet pre-set targets for the elimination of TB even before the COVID-19 pandemic began. A collaborative approach to achieve TB elimination, one that engages all care providers, has recently been emphasized by the STOP-TB Partnership. Among TB elimination strategies, frontline providers (e.g., family physicians, emergency room physicians, and others) are well positioned to identify candidates for the treatment of latent TB infection, and make the diagnosis of infection-spreading cases of TB in a timely manner, thereby interrupting forward-moving chains of transmission. Electronic medical records offer the promise of automating these processes. In this commentary, we promote broader engagement of the workforce across multiple sectors of medicine to reduce TB associated morbidity and mortality, interrupt transmission, and shrink the reservoir of latent TB infection.
\end{abstract}

\section{Résumé}

Le plus grand coût humain de la pandémie de SRAS-CoV-2, une maladie à évolution rapide, pourrait être son impact sur la riposte aux autres maladies. L'une d'elles est la tuberculose. Selon tous les indicateurs, les ressources de soins de santé détournées et les programmes de santé publique perturbés pour lutter contre la COVID-19 vont exacerber la pandémie de tuberculose, dont l'évolution est plus lente. Il faut s'attendre à une régression de plusieurs années dans les efforts pour éliminer la tuberculose. C'est une prédiction qui concerne particulièrement le Canada, qui a à maintes reprises été incapable de respecter les objectifs préétablis d'élimination de la tuberculose, même avant la pandémie de COVID-19. Le Partenariat Halte à la tuberculose promulgue depuis peu une démarche concertée, impliquant tous les prestataires de soins, pour parvenir à éliminer la tuberculose. Entre autres stratégies d'élimination, on compte sur les prestataires de première ligne (médecins de famille, médecins d'urgence et autres), bien placés pour repérer les personnes candidates au traitement de la tuberculose-infection (latente) et pour diagnostiquer les cas de tuberculose-maladie (active) dans les meilleurs délais, ce qui interromprait les chaînes de transmission en mouvement. Le dossier médical électronique recèle la promesse d'automatiser ces processus. Dans notre commentaire, nous préconisons une plus grande mobilisation de la main-d'œuvre de plusieurs secteurs de la médecine afin de réduire la morbidité et la mortalité associées à la tuberculose, d'en interrompre la transmission et de réduire la taille du réservoir d'infection tuberculeuse latente.

Keywords Pulmonary tuberculosis $\cdot$ Public health $\cdot$ Diagnosis

Mots-clés Tuberculose pulmonaire $\cdot$ santé publique $\cdot$ diagnostic

Richard Long

rlong@ualberta.ca

1 Department of Medicine, University of Alberta, Edmonton, Alberta, Canada
2 Department of Emergency Medicine, University of Alberta, Edmonton, Alberta, Canada

3 School of Public Health, University of Alberta, Edmonton, Alberta, Canada 


\section{Introduction}

In 2016, tuberculosis (TB) surpassed HIV/AIDS as the leading cause of death from a single infectious agent, globally (World Health Organization 2019). This position was maintained by TB until the emergence of severe acute respiratory syndrome coronavirus-2 (SARS-CoV-2), and the resultant COVID-19 pandemic in late 2019. Now, as COVID-19 becomes a vaccine-preventable disease and vaccine roll-out gains momentum, TB is expected to reassume this grim distinction. In fact, modeling studies suggest, and early observational data confirm, that the TB pandemic is greatly exacerbated as SARS-CoV-2 spreads across the world (Stop TB Partnership 2020; Migliori et al. 2020; McQuaid et al. 2021). Potential explanations include the restricted movement of people, social distancing and lock-downs, and diversion of healthcare resources designed to combat COVID-19, delayed diagnosis of TB, and ongoing transmission in the community, along with significant disruptions to contact tracing and the treatment of latent TB infection (LTBI) (Long et al. 2020). In responding to these dual pandemics, Canada is not immune to the consequences of these disruptions as they pertain to TB services.

The relatively low overall rate of TB disease in Canada (4.9/ 100,000 population in 2017) obfuscates substantially elevated risk of disease among vulnerable subpopulations (LaFreniere et al. 2019). Currently, almost $90 \%$ of all TB cases in Canada occur in two minority groups: 1) Indigenous peoples, especially those living in communities in the middle and far north, and 2) immigrants and/or travellers to Canada, especially those arriving from high TB incidence countries (LaFreniere et al. 2019). Despite these facts, Canada has failed to achieve any TB preelimination targets to date. These include a National Consensus Conference target of a 5\% annual reduction in the number of new cases set in 1997, a WHO Global Plan to Stop TB 20062015 target of an incidence of 3.6 per 100,000 population by 2015 set in 2006, and thus far, a WHO End TB Strategy target of an incidence of 1 case per 100,000 population by 2035, set in 2014 (Health Canada 1997; Stop TB Partnership, World Health Organization 2006; World Health Organization 2015). The ultimate target is elimination, defined as 1 case per million population by 2050 (World Health Organization 2015). Most recently, WHO and the Stop TB Partnership have emphasized the need for a collaborative approach to eliminate TB, one that engages all care providers - a recommendation that offers an untapped potential for Canada (World Health Organization 2018).

From a clinical and public health perspective, the elimination of TB is achieved by implementing two equally important approaches. These are preventing TB among those already infected but who have not yet developed disease, and interrupting transmission in those who have developed TB and have an infection-spreading phenotype. The first relies on latent tuberculosis infection (LTBI) testing of persons with an epidemiological risk of infection, and at the same time a high risk of progressing to disease in the presence of an infection using either of two immunological tests - the tuberculin skin test (TST) or interferon gamma release assay (IGRA) (Public Health Agency of Canada 2014). Once identified, clients should be offered and hopefully both accept and complete a satisfactory course of preventive therapy. Local provincial/territorial TB prevention and care programs typically oversee this process; however, frontline providers may, in the future, play a larger role. Such providers are well positioned to educate clients on the individual and public good of preventive therapy and, in turn, help to reduce stigmatization. The second-making a timely diagnosis of infection-spreading cases - depends upon the recognition of such cases by family physicians, emergency department physicians, and other frontline providers.

\section{Identifying and treating LTBI in persons at increased risk to reactivate}

The process of identifying the best candidates for the treatment of LTBI has become clearer, and their treatment has become simpler in recent years. Persons with a high epidemiologic risk for having LTBI (see below), and one or more high or moderately high risk factors for reactivation, which now includes younger, recently arrived immigrants from high TB incidence countries with a high titre IGRA test result ( $>4$ IU/ $\mathrm{ml}$ ), are easily identified (Winje et al. 2018; Ledesma et al. 2021). IGRAs are a one-stop blood test that provide a digital readout. Accordingly, there is no interobserver variability, such as that reported with the use of the TST. They are not, however, without limitations. For example, IGRAs are more costly and increase laboratory demand; on occasion, results may be indeterminate or falsely positive. Finally, there is strong evidence supporting the safety and efficacy of shorter regimens for the treatment of LTBI (see Table 1). These regimens are more likely to be completed, and are equally if not better tolerated than the heretofore standard therapy -9 months of isoniazid (Menzies et al. 2008; Menzies et al. 2018; Diallo et al. 2018; Hong Kong Chest Service Tuberculosis Research Centre, MBMRC 1992; Whalen et al. 1997; Martinson et al. 2011; Spyridis et al. 2007; Sterling et al. 2018). The importance of controlling the "seedbeds of tuberculosis" (finding and treating LTBI) was recently emphasized in a Lancet series on TB elimination (Rangaka et al. 2015). The identification of candidates who would most benefit from treatment for LTBI is a process with the potential for automation, particularly as provinces, territories, and other high-income countries adopt a single electronic medical record (EMR). 
Table 1 Shorter regimens for the treatment of LTBI approved for use in Canada

\begin{tabular}{llll}
\hline Regimen & Duration & Adverse events & Efficacy \\
\hline RIF (daily) & 4 months & $\begin{array}{c}\text { Potential drug-drug interactions; hematologic reactions } \\
\text { (thrombocytopenia, leukocytopenia); hepatoxicity; } \\
\text { rash; gastrointestinal intolerance }\end{array}$ \\
$\begin{array}{l}\text { Potential drug-drug interactions; hematologic reactions } \\
\text { (thrombocytopenia, leukocytopenia); hepatoxicity; } \\
\text { rash; gastrointestinal intolerance }\end{array}$ & $\begin{array}{l}\text { Possible hypersensitivity; potential drug-drug interactions; } \\
\text { hepatoxicity; rash }\end{array}$ \\
$\begin{array}{l}\text { INH/RPT } \\
\text { (once weekly DOPT) }\end{array}$ & 3 months & Eq. & Eq. 9INH \\
\hline
\end{tabular}

$I N H$, isoniazid; $R I F$, rifampin; $R P T$, rifapentine; $D O P T$, directly observed preventive therapy

These regimens may be prescribed in adults, adolescents, and children (INH/RPT only in children $>2$ years of age), as well as in people living with HIV/ AIDS

\section{Recognizing infectious pulmonary TB}

Given the low prevalence of TB in Canada and other highincome countries, frontline providers may rarely encounter patients with not yet diagnosed TB; however, there are some clues to facilitate the recognition of the most infectious pulmonary cases. By far, they are those with sputum smearpositive (positive for acid-fast bacilli [AFB] on microscopy) adult-type pulmonary TB (Lau et al. 2016). "Adult-type" pulmonary TB is defined as upper lung zone disease with or without cavitation, without discernible adenopathy, on chest radiograph (see Fig. 1) (Heffernan et al. 2020; Long 2015). These cases generally present with classical symptoms and a typical chest radiograph (Heffernan et al. 2020). When taken in combination with epidemiologic risks, these characteristics will identify most cases of infectious pulmonary TB, though the collection of epidemiological risks may not be systematic. The significance of these epidemiological risks is critical to obtaining a valid diagnosis of pulmonary TB. This activity also has the potential for automation (Lau et al. 2016; Heffernan et al. 2020; Long 2015).

In a study of emergency department (ED) utilization by patients prior to receiving a diagnosis of TB, the consequences of missing the diagnosis were highlighted. Over an 81-month period in the province of Alberta, Canada, more than half of all culture-positive pulmonary TB

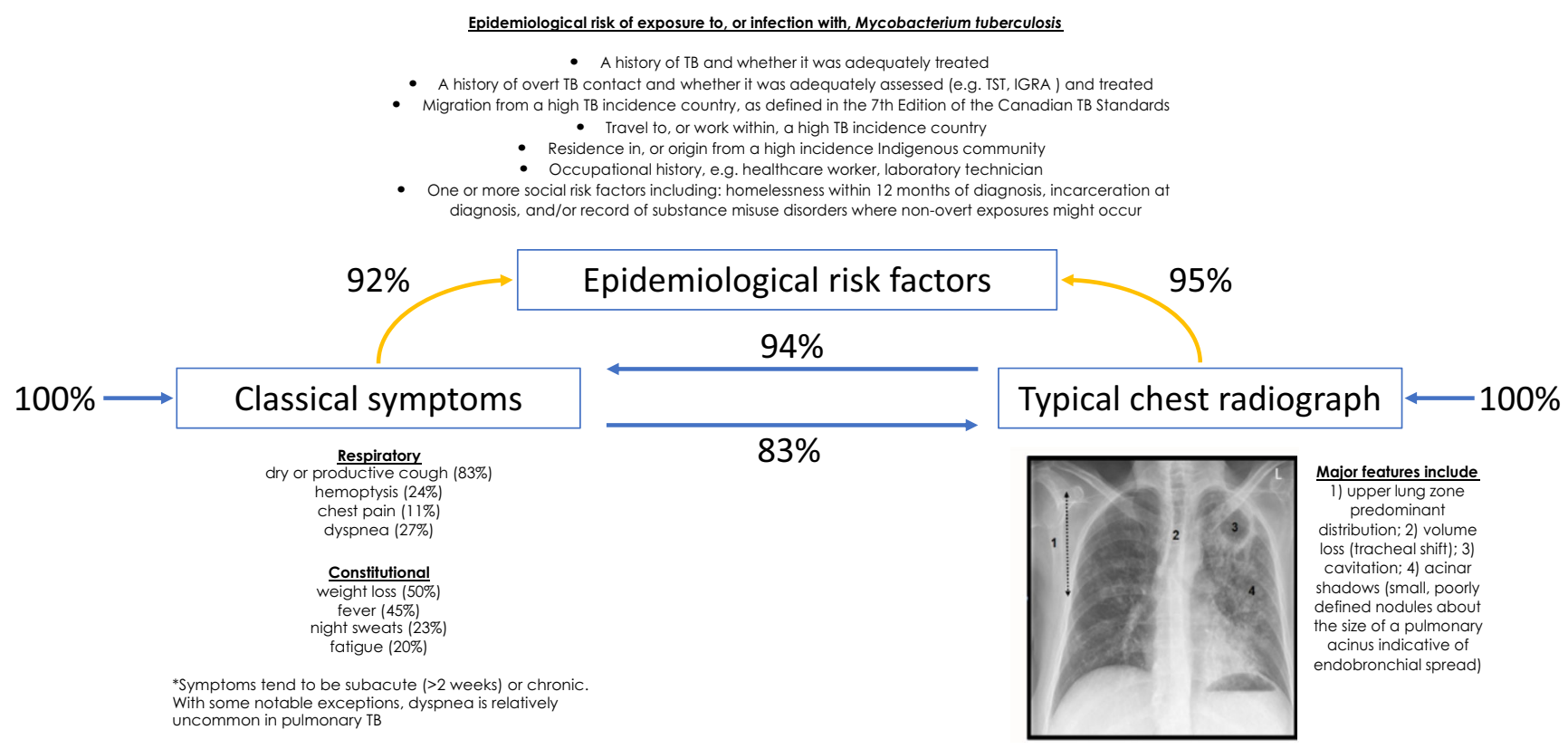

Legend: When either of the triggers, symptoms or a "typical" chest radiograph are present, they represent the most likely entry points to the healthcare system that defines the experiential interface between patient and provider. These triggers in the presence of one or more epidemiologic risk factor for latent TB infection, should increase suspicion of infectious pulmonary TB.

Three other pieces of information add to the likelihood that the pulmonary process is TB. These are a documented failure to respond to broad spectrum antibiotics (fluroquinolones excepted), the presence of a medical risk factor known to increase the risk of progression of LTBI to active disease, and the presence of anemia with a normal or low leukocyte count (see Long (2015)).

Fig. 1 Identifying infectious pulmonary TB, in practice 
patients attended an ED on one or more occasions $(75 \%$ on more than one occasion) in the 6 months antedating their diagnosis (Heffernan et al. 2021). At $90 \%$ of the visits, TB was missed. ED attendees were responsible for generating $60 \%$ of all secondary cases in the study period, and were more likely to die of TB than non-attendees. These findings underscore the importance to public and individual health of making more timely diagnoses of TB.

\section{Further reflection}

The WHO/STOP-TB Partnership adjuration to engage all care providers in the elimination of TB antedates the COVID-19 pandemic. The biomedical (clinical) focus of this commentary is not meant to minimize the importance to any TB elimination strategy of expanded and timely surveillance, addressing the social determinants of TB, and achieving health equity. As COVID-19 has rudely reminded us all, each of these is important. With respect to the engagement of all care providers, specifically, COVID-19 would appear to be exhorting us to find efficiencies and make better use of technology — such as remote care-to build a more resilient system. One such innovation, offered earlier, is to build algorithms into electronic medical records that identify candidates for treatment of LTBI and to link clinical, radiographic, and epidemiological characteristics that facilitate the diagnosis of infection-spreading cases. It is likely that the timely and proper identification of these groups will become increasingly challenging in the future as greater success in reducing their numbers is achieved.

\section{Conclusion}

Shrinking the reservoir of LTBI and interrupting the transmission of TB with a view to preventing secondary cases are the two major clinical and public health-oriented approaches to TB elimination. Family physicians, emergency physicians, and other frontline providers are key partners in the successful pursuit of these approaches. As has been shown during the COVID-19 pandemic, collaboration across many sectors of care can achieve enormous gains and we should be mobilizing this experience, as well as EMR advancements, as we turn our attention back to TB in 2021 .

Author contributions $\mathrm{CH}$ conceived of this work; all the authors contributed to the writing, added references, and edited the final draft before submission.
Data availability This work does not report any primary nor secondary data.

\section{Declarations}

Conflict of interest The authors declare that they have no material conflicts of interest. BR's research is supported by a Scientific Director Grant (SOP 168483) from the Canadian Institutes of Health Research (CIHR; Ottawa, ON).

Ethical approval Not applicable.

\section{References}

Diallo, T., Adjobimey, M., Ruslami, R., et al. (2018). Safety and side effects of rifampin versus isoniazid in children. $N$ Engl J Med, 370, 454-463.

Health Canada. (1998). Proceedings of the National Consensus Conference on Tuberculosis. December 3-5, 1997. Can Comm Dis Rep 24, S2.

Heffernan, C., Barrie, J., Doroshenko, A., et al. (2020). The prompt recognition of infectious pulmonary tuberculosis is critical to achieving elimination goals: a retrospective cohort study. BMJ Open Respir Res, 7, e000521.

Heffernan, C., Paulsen, C., Asadi, L., et al. (2021). Individual and public health consequences associated with a missed diagnosis of pulmonary tuberculosis in the emergency department: a retrospective cohort study. PLoS One, 16, e0248493.

Hong Kong Chest Service Tuberculosis Research Centre, MBMRC. (1992). A double-blind placebo-controlled clinical trial of three antituberculosis chemoprophylaxis regimens in patients with silicosis in Hong Kong. Am Rev Respir Dis, 145, 36-41.

LaFreniere, M., Hussain, H., He, N., et al. (2019). Tuberculosis in Canada: 2017. Can Commun Dis Rep, 45, 67-74.

Lau, A., Barrie, J., Winter, C., et al. (2016). Chest radiograph patterns and the transmission of tuberculosis: implications for automated systems. PLoS One, 11, e0154032.

Ledesma, J. R., Ma, J., Zheng, P., et al. (2021). Interferon-gamma release assay levels and risk of progression to active tuberculosis: a systematic review and dose-response meta-regression analysis. BMC Infect Dis, 21, 467.

Long, R. (2015). Making a timely diagnosis of pulmonary tuberculosis. Can Respir J, 22, 317-321.

Long, R., King, M., Doroshenko, A., et al. (2020). Tuberculosis and COVID-19 in Canada. EClinicalMedicine, 27, 100584.

Martinson, N. A., Barnes, G. L., Moulton, L. H., et al. (2011). New regimens to prevent tuberculosis in adults with HIV infection. $N$ Engl J Med, 365, 11-20.

McQuaid, C. F., Vassall, A., Cohen, T., et al. (2021). The impact of COVID-19 on TB: A review of the data. IJTLD, 25, 436-446.

Menzies, D., Long, R., Trajman, A., et al. (2008). Adverse events with 4 months of rifampin therapy or 9 months of isoniazid therapy for latent tuberculosis infection: a randomized trial. Ann Intern Med, 149, 689-697.

Menzies, D., Adjobimey, M., Ruslami, R., et al. (2018). Four months of rifampin or nine months of isoniazid for latent tuberculosis in adults. N Engl J Med, 379, 440-453.

Migliori, G., Thong, P. M., Akkerman, O., et al. (2020). Worldwide effects of coronavirus disease pandemic on tuberculosis services, January-April 2020. Emerg Infect Dis, 26, 2709-2712.

Public Health Agency of Canada, Canadian Thoracic Society. (2014). Canadian tuberculosis standards, 7th edition. Ottawa: PHAC. Available at: https://www.canada.ca/en/public-health/services/ 
infectious-diseases/canadian-tuberculosis-standards-7th-edition. html. Accessed 15 January 2021.

Rangaka, M. X., Cavalcante, S. C., Marais, B. J., et al. (2015). Controlling the seedbeds of tuberculosis: diagnosis and treatment of tuberculosis infection. Lancet, 386, 2344-2353.

Spyridis, N. P., Spyridis, P. G., \& Gelesme, A. (2007). The effectiveness of a 9-month regimen of isoniazid falone versus 3-and 4- month regimens of isoniazid plus rifampin for threatment of latent tuberculosis infection in children: results of an 11-year randomized study. Clin Infect Dis, 45, 715-722.

Sterling, T. R., Villarino, M. E., Borisov, A. S., et al. (2018). Three months of rifapentine and isoniazid for latent tuberculosis infection. $N$ Engl J Med, 365, 2155-2166.

Stop TB Partnership, Imperial College, Avenir Health, Johns Hopkins University, USAID. (2020). The potential impact of the COVID19 response on tuberculosis in high-burden countries: a modelling analysis. Geneva: Stop TB Partnership. Available at: http://www. stoptb.org/assets/documents/news/Modeling\%20Report_1\% 20May\%202020_FINAL.pdf. Accessed 15 January 2021.

Stop TB Partnership, World Health Organization. (2006). Global plan to stop TB 2006-2015. Geneva: WHO. Available at: http://www. stoptb.org/assets/documents/global/plan/GlobalPlanFinal.pdf. Accessed 15 January 2021.
Whalen, C. C., Johnson, J. L., Okwera, A., et al. (1997). A trial of three regimens to prevent tuberculosis in Ugandan adults infected with the human immunodeficiency virus. Uganda-Case Reserve University Research Collaboration. N Engl J Med, 337, 801-808.

Winje, B. A., White, R., Syre, H., et al. (2018). Stratification by interferon- $\gamma$ release assay level predicts risk of incident TB. Thorax, 73, 652-661.

World Health Organization. (2015). The end TB strategy. Geneva: WHO. Available at: https://www.who.int/tb/post2015_strategy/en. Accessed 15 January 2021.

World Health Organization. (2018). Public-private mix for TB prevention and care: a roadmap. Geneva: WHO. Available at: https://www. who.int/tb/publications/2018/PPMRoadmap/en. Accessed 15 January 2021.

World Health Organization. (2019). Global tuberculosis report 2019. Geneva: WHO. Available at: https://apps.who.int/iris/bitstream/ handle/10665/329368/9789241565714-eng.pdf. Accessed 15 January 2021.

Publisher's note Springer Nature remains neutral with regard to jurisdictional claims in published maps and institutional affiliations. 